
\title{
28 Research Square \\ Effects of episodic slow slip on seismicity and stress near a subduction-zone megathrust
}

\section{Saeko Kita ( $\sim$ kita@kenken.go.jp )}

Building Research Institute

\section{Heidi Houston}

University of Southern California

\section{Suguru Yabe}

National Institute of Advanced Industrial Science and Technology

\section{Sachiko Tanaka}

National Institute of Earth Science and Disaster Resilience

\section{Youichi Asano}

National Research Institute for Earth Science and Disaster Resilience

\section{Takuo Shibutani}

DPRI, Kyoto University

\section{Naoki Suda}

Hiroshima University

\section{Article}

Keywords: slow slip, earthquakes, tectonics

Posted Date: May 26th, 2021

DOl: https://doi.org/10.21203/rs.3.rs-343830/v1

License: (c) (i) This work is licensed under a Creative Commons Attribution 4.0 International License.

Read Full License

Version of Record: A version of this preprint was published at Nature Communications on December 1st, 2021. See the published version at https://doi.org/10.1038/s41467-021-27453-8. 


\title{
Title: Effects of episodic slow slip on seismicity and stress near a subduction-zone
} megathrust

Authors: Saeko Kita ${ }^{1 *}$, Heidi Houston², Suguru Yabe ${ }^{3}$, Sachiko Tanaka ${ }^{4}$, Youichi Asano ${ }^{4}$, Takuo Shibutani ${ }^{5}$, Naoki Suda ${ }^{6}$

\author{
Affiliations: \\ ${ }^{1}$ Building Research Institute, National Research and Development Agency, Tsukuba, \\ Ibaraki, Japan \\ ${ }^{2}$ University of Southern California, Los Angeles, California, USA \\ ${ }^{3}$ National Institute of Advanced Industrial Science and Technology (AIST), Tsukuba, \\ Ibaraki, Japan \\ ${ }^{4}$ National Institute of Earth Science and Disaster Resilience (NIED), Tsukuba, Ibaraki, Japan \\ ${ }^{5}$ DPRI, Kyoto University, Uji, Kyoto, Japan \\ ${ }^{6}$ Hiroshima University, Higashi-Hiroshima, Hiroshima, Japan
}

* Currently at the Department of Earth and Planetary Science and Berkeley Seismolab, University of California, Berkeley, California, USA

\section{Correspondence to: Saeko Kita (kita@kenken.go.jp)}

\begin{abstract}
Slow slip phenomena deep in subduction zones reveal cyclic processes downdip of locked megathrusts. Here we analyze seismicity within a subducting oceanic slab under Kii Peninsula, Japan, spanning nearly 50 major deep slow slip and tremor episodes over 17 years. Changes in rate, $b$-values, and stress orientations of inslab seismicity are temporally associated with the slow slip episodes. Furthermore, although stress orientations in the slab below these slow slips may rotate slightly, inslab orientations 20 to $50 \mathrm{~km}$ updip from there rotate significantly, suggesting previously-unrecognized transient slow slip occurs on the plate interface updip. We infer that fluid migrates from slab to interface, promoting episodes of slow slip, which break mineral seals, letting fluid migrate 10's of $\mathrm{km}$ further updip along the interface where it promotes transient slow slips. The proposed methodology, based primarily on inslab seismicity, may help monitor plate boundary conditions and slow slip phenomena, which can signal the beginning stages of megathrust earthquakes.
\end{abstract}

Main: Slip on the plate interface has the potential to affect the stress field and seismicity within a subducting slab. Slow slip has been associated with some great megathrust earthquakes during the slip nucleation and/or stress accumulation process ${ }^{1}$. Seismicity and fluid within a down-going ocean slab may also be closely related to the occurrence of slow slip phenomena. Studies have examined the interaction between slow slip and in-slab earthquakes, showing that 
even slow deformation on the plate interface has the potential to change the stress field ${ }^{2}$ and seismicity $^{3}$ within the subducting slab. An analysis ${ }^{2}$ of the Hikurangi subduction zone, which is generally in down-dip tension, found a change in orientation of the least compressive stress $\sigma 3$ of approximately 15 degrees, using 14 months of in-slab focal mechanisms associated with four slow slip events of up to M6.8.

In the present study, we examine stress changes, seismicity rate variations, and b-value variations relative to the timing of about 50 episodic tremor and slip (ETS) events beneath the Kii Peninsula (Fig. 1a) using 17 years of data, paying special attention to the stress changes in the upper-plane of the double seismic zone. We used the Japan Meteorological Agency earthquake catalog $(\sim 150,000$ earthquakes), the National Institute of Earth Science and Disaster Resilience (NIED) tremor catalog ${ }^{4}(\sim 10,6001$-hr tremors), the upper surface of the Philippine Sea Plate estimated by receiver functions ${ }^{5,6}$, the NIED P-wave polarity focal mechanism catalog $(\mathrm{M}>2.0)$, and a stress tensor inversion method ${ }^{7}$.

\section{Changes of stress orientations in the subducting slab}

We determined times of approximately 50 large ETS events beneath the Kii Peninsula from January 2002 to March 2019 using hypocenter information for tremors detected by NIED ${ }^{4,8,9}$ (Fig. 1b). In the Kii Peninsula, ETS events typically have moment magnitudes of approximately 6 , recurrence intervals of approximately 6 months, and durations of a week or less ${ }^{4,10}$. The center of the ETS duration was used to define each ETS time. We selected 3,410 in-slab events $(0<\mathrm{M}<5.5)$ from the JMA earthquake catalog between January 2002 and March 2019, based on the normal distance from the inferred plate interface ${ }^{5,6}$. In Fig. 1b, we then categorized slab seismicity and available focal mechanisms relative to the occurrence times of the nearby ETS (i.e., two or three months before or after the ETS time) (Methods). The results of the stress tensor inversions are shown in Fig. 2. The temporal changes in seismicity and b-values relative to the times of the nearest ETS are shown in Fig. 3.

Double seismic planes in the Philippine Sea Plate beneath the Kii Peninsula have been proposed previously ${ }^{11}$, and are now clearly revealed in Figs. $2 b$ through $2 \mathrm{~d}$. The upper and lower planes have sufficiently different stress regimes that they must be analyzed separately. We focus on the upper plane because we expect that the stress regime in this region is more directly influenced by slip at the plate boundary than that in the inter- and lower-plane regions (see Figs. 2i, 2j, Supplementary Text 1, Supplementary Figs. 1e and 1f) due to the proximity to the plate boundary (Fig. 1c).

For detailed analyses, we further divided upper-plane events into events in the ETS zone and events updip of the ETS zone (Figs. 1 and $2 \mathrm{a}$ through $2 \mathrm{~d}$ ). Figures $2 \mathrm{e}$ and $2 \mathrm{f}$ show the stress tensor inversion results for upper-plane events updip of the ETS zone for combined regions A, $\mathrm{B}$, and $\mathrm{C}$ using the focal mechanisms for events within two months before and after the ETS times (see Supplementary Figs. 1a, $1 \mathrm{~b}$ and Supplementary Table 1). The best fit $\sigma 1$ before ETS is located closer to horizontal than to the dip of the plate interface. After ETS, $\sigma 1$ changes by approximately 15 degrees, lying farther above the plate interface dip. The $90 \%$ confidence limits for $\sigma 1$ after ETS do not overlap those before ETS. In contrast, stress inversion of upperplane events just beneath the ETS zone (Figs. 2g, 2h, Supplementary Figs. 1c and 1d) yields only a small stress change after ETS. The best fit $\sigma 1$ before the ETS is horizontal and steepens 
by approximately 5 degrees afterwards to become parallel to the plate interface dip. Bootstrapping in Supplementary Fig. S7 demonstrates the robustness of the stress changes, particularly for the updip region. The stress ratios $\mathrm{R}$ for the results in Figs. 2e through $2 \mathrm{~h}$ range between approximately 0.7 and 0.85 .

The plate boundary between the overlying and oceanic plates is likely fully coupled in the region anticipated to generate great megathrust earthquakes, whereas the plate boundary in the ETS zone undergoes transient slow slip and is only partially coupled ${ }^{12,13}$. The change in stress orientations suggests that previously-unrecognized transient slow slip occurs on the plate interface 20 to $50 \mathrm{~km}$ updip. This updip region overlaps inferred asperities of anticipated great earthquakes (Figs. 1a through 1c) ${ }^{10}$. We propose two possibilities to explain the larger stress change we observe updip.

First, larger, but less frequent slow slip events may occur on the plate interface updip, compared to ETS recurrence periods of about 6 months. This appears consistent with reported along-dip trends in Cascadia ${ }^{14}$ and Nankai ${ }^{15}$ in which size and recurrence intervals of tremor bursts and

105 low frequency earthquakes increase updip through the ETS zone ${ }^{14}$, with the degree of plate coupling perhaps controlled by the temperature structure ${ }^{16}$. Alternatively, the same slip on the updip plate interface as in the ETS zone could generate more rotation of updip stress axes, if the average effective rigidity there is greater. Higher fluid pressure, and hence lower effective rigidity, in the slab below ETS is suggested by previous studies of $\mathrm{Vp} / \mathrm{Vs}^{6}$ and attenuation ${ }^{17}$, 110 and plays a key role in our interpretation below.

\section{Seismicity changes in the subducting slab}

Cumulative numbers of in-slab seismicity versus time relative to ETS times in the three regions are shown in Fig. 3a. Increased seismicity rates appear to start approximately two to four weeks 115 before ETS times and to decrease slightly after ETS times. Cumulative numbers of seismicity versus time relative to ETS times in the combined regions were calculated for three levels of catalog completeness $(\mathrm{Mc}=0.5,0.7,1.0)$ (Fig. 3b). Increased seismicity rates clearly start approximately two weeks before ETS times and decrease after ETS times. In addition, the bvalues, which indicate the relative abundance of small and large earthquakes, of the in-slab earthquakes in the combined regions after the ETS were smaller than those before ETS (Fig. 3c, Supplementary Text 2, and Supplementary Fig. 3a though 3b). In summary, b-values are generally larger before the ETS times than after, and have a clear peak one to two months before the ETS times (Fig. 3d). A peak in b-values before the ETS times is also observed for the upper-plane seismicity alone (see Supplementary Fig. 4 and Supplementary Text 3). For 125 the evolution of the stress ratio and stress orientations with time, see Supplementary Figs. 6 through 9 and Supplementary Texts 4 and 5.

These changes in seismicity rate and b-values associated with ETSs are consistent with studies of injection seismicity in Switzerland ${ }^{18}$ and "geofluid injection" seismicity beneath northeastern $\operatorname{Japan}^{19}$. Both the b-value and seismicity in the inland crust have been shown to increase $(b \sim 2)$ just after the M9 Tohoku earthquake and to decrease $(b \sim 1)$ within 50 days ${ }^{19}$. Moreover, scaled friction and stress drops for inland events increased within 50 days after the M9 event in that region. High pore pressure and low effective friction at the fault are expected to occur simultaneously in the case of an abundance of fluid. Geofluid injection in the inland 
crust from the uppermost mantle could have occurred just after the M9 event because the compressional stress field in this region decreased due to the event ${ }^{19}$. After the injection fluid started to disperse, a decrease in b-values, a decrease in seismicity rate, and an increase in friction on existing faults in the inland crust simultaneously occurred ${ }^{19}$.

The temporal variation of b-values and seismicity rate in the slab associated with ETS, thus 140 appears to be related to fluid migration. Because high pore pressure promotes earthquake occurrence, an interpretation of our results, consistent with refs. 18, 19, is that high b-value peaks occur due to fluid accumulation in the oceanic slab 1.5 months before the ETS times. The decrease in b-values appears to correspond to the start of fluid migration out of the slab to the plate boundary (Figs. 3d and 3e). The depth of tremors (30 to $40 \mathrm{~km}$ ) is consistent with the

145 location of low P- and S-wave velocities and high Vp/Vs in the oceanic crust ${ }^{6}$, which could be a result of fluid migration from the slab into the plate boundary.

A recent geological and simulation study inferred that quartz vein seals develop on the plate boundary at a depth of approximately $30 \mathrm{~km}$ within 0.8 to 1.6 years, and it was proposed that

150 quartz vein formation cycles could be closely related to ETS cycles ${ }^{20}$. Since the formation of quartz veins is generally associated with hydrothermal activity, we suggest that the quartz vein sealing cycle could also be related to the in-slab earthquake seismicity studied here. Since a low-attenuation zone is located above the tremor and LFEs in Kii Peninsula ${ }^{21,22}$, we suggest that the relatively impermeable low-attenuation zone in the overlying plate above ETS events can increase the pore pressure at the plate boundary, which could also be related to the process of quartz vein sealing. Our result that in-slab seismicity is still active after the b-values start to decrease (Figs. 3d and 3e) may imply that the quartz sealing increases high pore pressure near in-slab seismicity, as well as in the plate boundary.

\section{Possibility of aseismic slip updip of ETS zone}

In general, small- to middle-magnitude repeating earthquakes that occur on the plate boundary breaking the same fault area are evidence of creep on the plate boundary ${ }^{23}$. In the updip zone, two groups of offshore repeating earthquakes (shown in Figure $2 \mathrm{a}, 2 \mathrm{c}$ and $2 \mathrm{~d}$ as orange stars) occur a few times during our study period. In at least two cases, they occur shortly after ETSs 165 located 30-40 km down dip ${ }^{24}$. Additionally, a cluster of earthquakes (shown in Figures 2a and $2 \mathrm{~b}$ as orange small open dots) is located on the plate boundary also about $30 \mathrm{~km}$ updip of the ETS zone; its seismicity tends to increase approximately 1.5 months after ETS times (Fig. 3f). These observations imply that shortly after ETS times, transient slow slip can occur in the updip zone under and offshore Kii Peninsula. Aseismic slip on the plate interface updip of 170 tremor is also consistent with a GPS study suggesting the occurrence of some slow slip events in the updip zone beneath Kii Peninsula ${ }^{25}$ and with other GPS studies implying slip in the region updip of the ETS zone in Cascadia ${ }^{26,27}$, Shikoku ${ }^{28}$ and Tokai regions ${ }^{25}$.

Our analysis of in-slab earthquakes relative to ETS times suggests that high b-value and seismicity rates in the slab occur before the ETS due to fluid injection, perhaps by dehydration of oceanic crust and/or oceanic mantle. Our interpretation is shown schematically in Fig. 4. Fluid is produced in the oceanic slab and moves from the slab to the plate interface, generating higher pore pressure at the plate boundary. High pore pressure decreases the effective strength 180 of the plate boundary in the ETS zone, allowing ETS to occur. The slip is associated with a possible small rotation of the stress orientation beneath the ETS zone and a larger rotation 
beneath the region updip of ETS. This larger rotation occurs too far from ETS to be caused directly by it, but could be related to transient aseismic slip updip of the ETS zone. We propose that high pore pressure (and fluid) on the plate boundary disperses after the ETS due to rupturing of quartz vein seals. After ETS times, fluid on the plate boundary migrates from the ETS to the updip zone. Due to the accumulation of fluid, the interface of the updip region becomes less coupled and starts to creep faster. Thus, transient aseismic slip also occurs in the updip zone after the ETS times as implied by the repeating earthquakes ${ }^{24}$ and GPS evidence ${ }^{25}$ (Figure 3f), although these observations are too few to closely resolve the timing. Eventually, 190 stress orientations rotate back to the initial stress state. Different mineralogical, fluid, or temperature conditions in the updip and near-ETS regions may produce the observed contrasting effects of ETS on plate-boundary coupling in the two regions. Our new approach using focal mechanisms and seismicity in the slab can supplement the recent monitoring efforts for plate-boundary and ETS phenomena using only tiltmeters and GPS, which are sparse in remote regions, and subject to bad-weather (such as typhoons or heavy rain). The proposed simple methodology could contribute to prediction techniques for future megathrust earthquakes. 


\section{Stress regime analysis}

To obtain stress orientations and the stress ratio, we performed stress tensor inversions using software from Ref. 7 and focal mechanisms based on P-wave polarities by the National Institute of Earth Science and Disaster Resilience (NIED) catalog $(M>2.0)$. In the examination of the temporal relationship of in-slab events to ETS, we categorized slab seismicity relative to the occurrence times of nearby ETS (i.e., two or three months before or after) (Fig. 1b). We then combined the slab seismicity and events with focal mechanisms based on these relative occurrence times.

Confidence regions are estimated as follows. We assume that errors in the focal mechanisms are Gaussian with an estimated standard deviation of 20 degrees. These random errors are added to the mechanisms, which are then inverted for stress orientations. This process is repeated 200 times. We then estimate $90 \%$ confidence regions based on the $90 \%$ of the inversion results that lie closest to the optimal inversion result calculated from the original data.

In the stress tensor inversion analysis, the stress ratio $\mathrm{R}$ for focal mechanisms is defined 215 as follows:

$$
\mathrm{R}=(\sigma 1-\sigma 2) /(\sigma 1-\sigma 3)
$$

where $\sigma 1, \sigma 2$, and $\sigma 3$ are the maximum compressive stress, intermediate compressive stress, and minimum compressive stress, respectively. $\mathrm{R}>0.5$ indicates that a single-axis compression stress field is dominant in the study area, whereas $\mathrm{R}>0.5$ indicates that a single-axis tension stress field is dominant.

\section{B-value analysis}

We estimated the time evolution of b-values and seismicity rate relative to the ETS occurrence times. For the b-value calculation, we used the following relation:

$$
b=\frac{\log _{10} e}{\bar{M}-M_{c}}
$$

230 where $\log _{10} e=0.43429$ and $\mathrm{Mc}$ is the complete magnitude (i.e., lower limit of the detected magnitude $)^{29}$. The $95 \%$ confidence level for $b$-value estimations is given by $b / \sqrt{ } \mathrm{N}$ ( $\mathrm{N}$ : number of events) $)^{30}$.

\section{Spatial classification of in-slab events}

235 We identified in-slab earthquakes based on normal distance from the inferred plate interface estimated by receiver function analysis ${ }^{5,6}$. The plate model beneath Kii peninsula was estimated using 99 temporary as well as 55 permanent seismic stations, and is broadly similar to a previous model ${ }^{31}$ based on only permanent stations. The depths contours of this model $1^{5,6}$ are clearly consistent with the locations of low frequency earthquakes ${ }^{21,22}$ and repeating 240 earthquakes ${ }^{24}$ (Figs. $2 b$ through $2 d$ ). The available seismicity and focal mechanisms in the Kii Peninsula indicate that, as found in many subduction zones ${ }^{32}$, the downgoing slab is organized as a double seismic zone ${ }^{11,33}$ (Figs. $2 b$ through $2 d$ ) in which the upper and lower zones exhibit different stress regimes. Therefore, to analyze the stress regimes, we divided in-slab events with focal mechanisms into upper-plane events (Figs. 1b and Supplementary Figs. 1a through 1d) and other in-slab events (interplane and lower-plane events) (Supplementary Figs. 1e, and 1f) and performed stress tensor inversions (Figs. 2e through $2 \mathrm{j}$ and Supplementary Table 1). We classified in-slab events within $10 \mathrm{~km}$ of the plate interface (and at depths of 25 to $45 \mathrm{~km}$ ) 
as upper-plane events, whereas in-slab events farther from the interface were classified as interplane and lower-plane events. The classification of upper-plane events is similar to a previous study beneath northeastern Japan ${ }^{34}$.

For more detailed analyses, we further divided upper-plane events into events below the ETS zone and events 20 to $50 \mathrm{~km}$ updip of the ETS zone (Figs. 1, 2a through $2 \mathrm{~h}$, and Supplementary Figs. 1a through 1d). We define the ETS zone to lie within $20 \mathrm{~km}$ from the centers of the tremor sequences which are shown as blue, green, and red lines in Fig. 1a. 


\section{References and Notes:}

1. Obara, K., Kato, A., Connecting slow earthquakes to huge earthquakes. Science, 353 (6296), 253-257 (2016).

2. Warren-Smith, E., Fry, B., Wallace, L., Chon, E., Henrys, S., Sheehan, A., Mochizuki, K., Schwartz, S., Webb, S., Lebedev, S., Episodic stress and fluid pressure cycling in subducting oceanic crust during slow slip. Nature geoscience, 12, 475-48 (2019).

3. Han, J., Vidale, J. E., Houston, H., Chao, K., Obara, K., Triggering of tremor and inferred slow slip by small earthquakes at the Nankai subduction zone in southwest Japan. Geophys. Res. Lett., 41, 8053- 8060 (2014).

4. National Research Institute for Earth Science and Disaster Resilience, Activity of deep lowfrequency tremor in southwest Japan (November, 2018 - April, 2019). Report of the coordinating committee for earthquake prediction, 102, pp 299-305 (in Japanese)

5. Imai, M., Shibutani, T., Hirahara, K., Nakao, S., Structure around Philippine Sea slab beneath Kii Peninsula, Japan inferred from receiver function analyses, presented at AGU 2013 Fall Meeting, DI33A-2230, San Francisco, CA, 11 Dec 2013.

6. Shibutani, T., Hirahara, K., 3D seismic velocity structure beneath Kii Peninsula, southwestern Japan derived from receiver function analysis and seismic tomography, presented at IAG-IASPEI 2017, J08-P12, Kobe, Japan, 4 August 2017.

7. Vavryčuk, V., Iterative joint inversion for stress and fault orientations from focal mechanisms. Geophysical Journal International, 199, 69-77 (2014).

8. Maeda, T., Obara, K., Spatio-temporal distribution of seismic energy radiation from lowfrequency tremor in western Shikoku, Japan. J. Geophys. Res., 114, B00A09 (2009).

9. Obara, K., Maeda, T., Tanaka, S., Matsuzawa, T., Depth-dependent activity of non-volcanic tremor in southwest Japan. Geophys. Res. Lett., 37, L13306 (2010).

10. Obara, K., Phenomenology of deep slow earthquake family in southwest Japan: Spatiotemporal characteristics and segmentation. J. Geophys. Res., 115, B00A25 (2010).

11. Miyoshi, T., Ishibashi, K., Geometry of the Seismic Philippine Sea Slab beneath the Region from Ise Bay to Western Shikoku, Southwest Japan. J. Seismol. Soc. Jpn, 57, 139-152 (2004). 
12. Yokota, Y., Ishikawa, T., Watanabe, S., et al. Seafloor geodetic constraints on interplate coupling of the Nankai Trough megathrust zone. Nature, 534, 374-377 (2016).

13. Nishimura, T., Yokota, Y., Tadokoro, K., Ochi, T., Strain partitioning and interplate coupling along the northern margin of the Philippine Sea plate, estimated from Global Navigation Satellite System and Global Positioning System-Acoustic data. Geosphere, 14, 535-551 (2018).

14. Sweet, J. R., Creager, K. C., Houston, H., Chestler, S. R., Variations in Cascadia lowfrequency earthquake behavior with downdip distance. Geochemistry, Geophysics, Geosystems, 20, 1202- 1217 (2019).

15. Obara, K., Matsuzawa, T., Tanaka, S., Kimura, T., and Maeda, T., Migration properties of non-volcanic tremor in Shikoku, southwest Japan, Geophys. Res. Lett., 38, L09311 (2011).

16. Hyndman, R., Wang, K., Yamano, M., Thermal constraints on the seismogenic portion of the southwestern Japan subduction thrust. J. Geophys. Res., 100(B8), 15373-15392 (1995).

17. Kita, S., Matsubara, M., Seismic attenuation structure associated with episodic tremor and slip zone beneath Shikoku and the Kii peninsula, southwestern Japan, in the Nankai subduction zone. J. Geophys. Res. Solid Earth, 121, 1962-1982 (2016).

18. Bachmann, C. E., Wiemer, S., Goertz-Allmann, B. P., Woessner, J., Influence of porepressure on the event-size distribution of induced earthquakes. Geophys. Res. Lett., 39, L09302 (2012).

19. Yoshida, K., Saito, T., Urata, Y., Asano, Y., Hasegawa, A., Temporal changes in stress drop, frictional strength, and earthquake size distribution in the 2011 YamagataFukushima, NE Japan, earthquake swarm, caused by fluid migration. J. Geophys. Res. Solid Earth, 122, 10,379- 10,397 (2017).

20. Ujiie, K., Saishu, H., Fagereng, A., Nishiyama, N., Otsubo, M., Masuyama, H., Kagi, H., An explanation of epi- sodic tremor and slow slip constrained by crack-seal veins and viscous shear in subduction mélange. Geophys. Res. Lett., 45, 5371-5379 (2018).

21. Ohta, K., Ide, S., Precise hypocenter distribution of deep low-frequency earthquakes and its relationship to the local geometry of the subducting plate in the Nankai subduction zone, Japan. J. Geophys. Res., 116, B01308 (2011). 
22. Ohta, K., Ide, S. A precise hypocenter determination method using network correlation coefficients and its application to deep low-frequency earthquakes. Earth Planet Space, 60, 877-882 (2008).

23. Uchida, N. Detection of repeating earthquakes and their application in characterizing slow fault slip. Prog. Earth Planet Sci., 6, 40 (2019).

24. Igarashi, T. Catalog of small repeating earthquakes for the Japanese Islands. Earth Planets Space, 72, 73 (2020).

25. Kano, M., Kato, A., Detailed spatial slip distribution for short-term slow slip events along the Nankai subduction zone, southwest Japan. J. Geophys. Res. Solid Earth, 125, e2020JB019613 (2020).

26. Bruhat, L., Segall, P., Deformation rates in northern Cascadia consistent with slow updip propagation of deep interseismic creep, Geophysical Journal International, 211, 1, 427-449 (2017).

27. Bartlow, N. M. (2020). A long-term view of Episodic Tremor and Slip in Cascadia. Geophysical Research Letters, 47, e2019GL085303 (2020).

28. Kano, M., Kato, A., Obara, K. Episodic tremor and slip silently invades strongly locked megathrust in the Nankai trough. Scientific Reports, 9 (1), 9270 (2019).

29. Utsu, T., A method for determining the value of $b$ in a formula $\log n=a-b M$ showing the magnitude-frequency relation for earthquakes. Geophys. Bull., Hokkaido Univ., Hokkaido, Japan, 13, 99-103 (1965).

30. Aki, K., Maximum likelihood estimate of $\mathrm{b}$ in the formula $\log \mathrm{N}=\mathrm{a}-\mathrm{bM}$ and its confidence limits. Bull. Earthquake Res. Inst., Tokyo Univ., 43, 237-239 (1965).

31. Ueno, T., Shibutani, T. and Ito, K., Configuration of the continental Moho and Philippine sea slab in southwest Japan derived from receiver function analysis: relation to subcrustal earthquakes. Bulletin of the Seismological Society of America, 98 (5), 2416-2427 (2008).

32. Brudzinski, M.R., Thurber, C.H., Hacker, B.R, Engdahl, E.R., Global prevalence of double Benioff zones. Science, 316, 1472-1474 (2007).

33. Yamasaki, T., and Seno, T., Double seismic zone and dehydration embrittlement of the subducting slab. J. Geophys. Res., 108, 2212 (2003). 
34. Kita, S., Okada, T., Hasegawa, A., Nakajima, J., Matsuzawa, T., Existence of interplane earthquakes and neutral stress boundary between the upper and lower planes of the double seismic zone beneath Tohoku and Hokkaido, northeastern Japan. Tectonophysics, 496(1), 68-82 (2010).

Acknowledgments: We would like to thank K. Ujiie and M. Otsubo for discussions on quartz veins, and F. Hirose, A. Hasegawa, Y. Ito, and N. Uchida for seismological comments. We also would like to thank T. Igarashi for discussions on repeating earthquakes. We declare no competing financial interests. The present study was supported by JSPS KAKENHI Grant Numbers JP16H06475, JP16K21728, JP17K05637, 18KK0392, 19H04627, 20K04139 and a collaborative research grant from the Disaster Prevention Research Institute (DPRI), Kyoto University 28G-07.

\section{Author Information:}

$395 \quad$ Author contributions S.K. and H.H. analyzed the data, made the figures, wrote the manuscript, and interpreted the results. S.Y. contributed the interpretation of the results. S.T. contributed the tremor catalog and the interpretation of the results. Y.A. contributed selections of the focal mechanisms and a related discussion. T.S. contributed a discussion of the discontinuities and seismicity. N.S. contributed a discussion of LFEs and tremors.

Corresponding author

Saeko Kita

Ethics declarations:

Competing interests

The authors declare that they have no competing interests.

\section{Data and materials availability:}

410 The p-wave polarity focal mechanisms were obtained from NIED using the MOWLAS (http://www.hinet.bosai.go.jp/). The hypocenters were obtained from the JMA (https://www.data.jma.go.jp/svd/eqev/data/bulletin/hypo_e.html). The tremor and LFEs catalogs are available at the Slow Earthquake database (http://www-solid.eps.s.utokyo.ac.jp/ sloweq/). Additional data related to the present paper may be requested from the 415 authors.

\section{Code availability:}

The Matlab code for the stress tensor inversion method adopted in this paper is provided on the web page (https://www.ig.cas.cz/en/stress-inverse).

\section{Supplementary information:}

Supplementary Tables 1 through 4

Supplementary Figures 1 through 9 


\section{Supplementary Text 1 through 5}



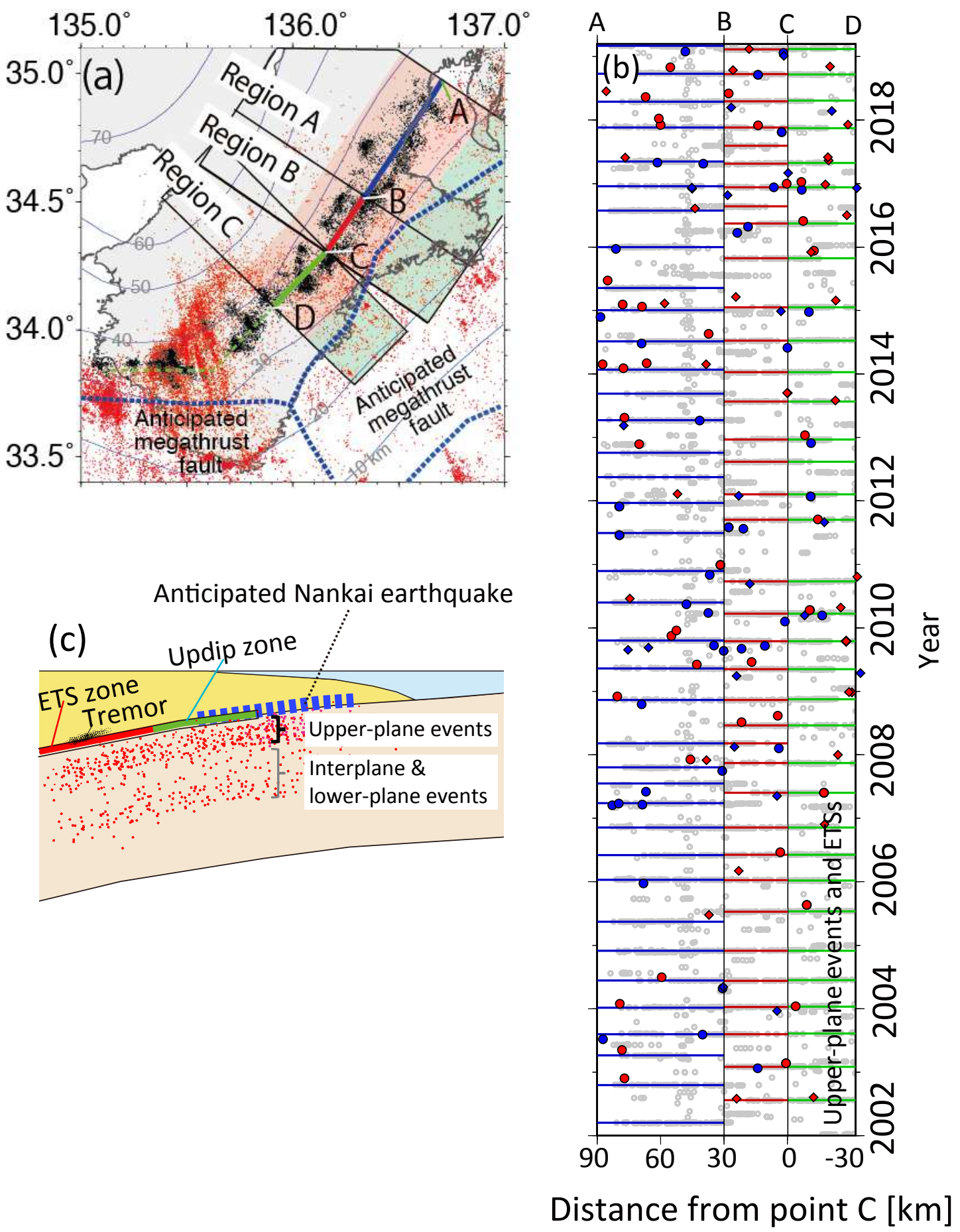

Fig. 1. Activity of episodic tremor and slip (ETS) and in-slab earthquakes. (a) Tremor (black dots) and slab seismicity (red dots) in Kii Peninsula. Thin black curves and blue dashed lines show the geometry of the Philippine Sea Plate ${ }^{5,6}$ and anticipated great megathrust earthquake ${ }^{10}$. Red and green shaded areas show the ETS zone and the region updip of ETS zone. (b) Tremor occurrence times versus distance along the strike of the subducting slab. Times of the major ETSs on different segments are shown by blue (region A, 38 times), red (region B, 37 times), and green (region C, 34 times) lines. The division of regions is shown in Fig. 1a. The distance along the strike is measured from point $\mathrm{C}$ in Fig. 1a. Gray circles indicate tremors. Solid blue circles and diamonds show upper-plane slab events with focal mechanisms, beneath the ETS zone and the region of updip of it, respectively, that occurred in two-month 
time windows before ETS. Solid red circles and diamonds show upper-plane slab events with focal mechanisms, beneath the ETS zone and the region updip of it, respectively, that occurred in two-month time windows after ETS. (c) Schematic cross-section of the area beneath Kii Peninsula. 


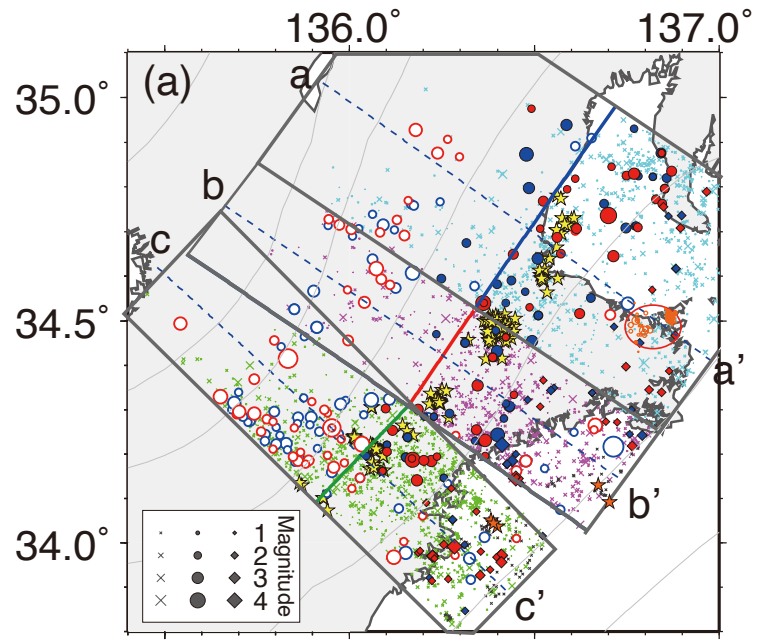

Before ETS After ETS
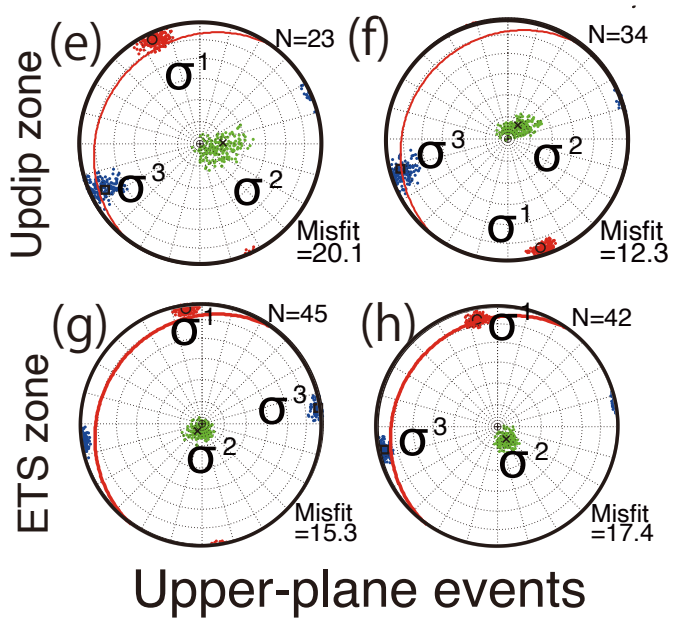

(Regions $\mathrm{A}+\mathrm{B}+\mathrm{C}$ )
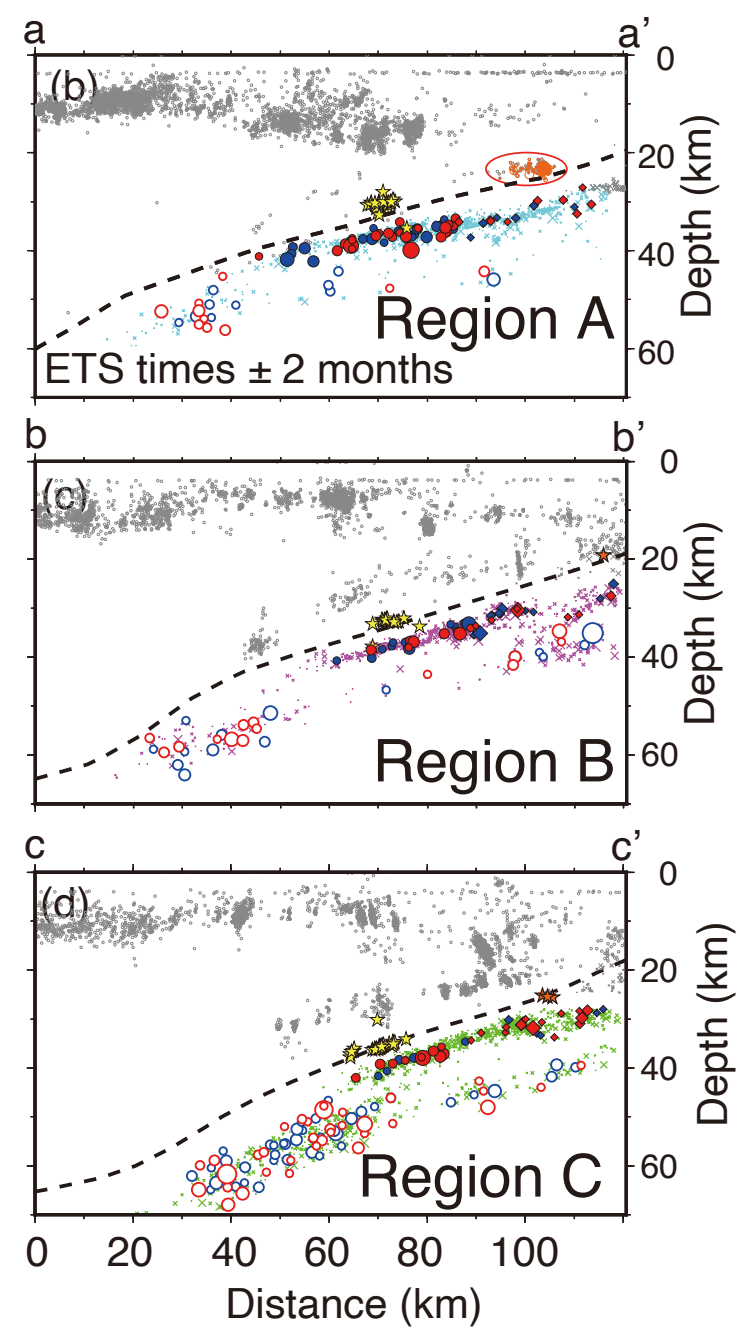
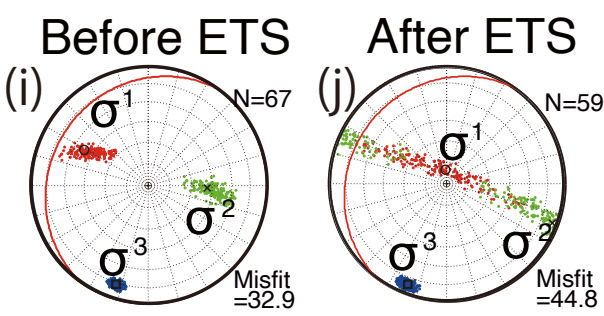

Interplane and lower-plane events

(Regions $\mathrm{A}+\mathrm{B}+\mathrm{C}$ )

Fig. 2. Seismicity and results of stress tensor inversions. (a) and (b-d) Map view and crosssections of three regions of in-slab seismicity under Kii Peninsula. Explanations of red and blue solid symbols (diamonds and circles) are as in Fig. 1b. Blue and red open circles indicate interplane and lower-plane slab events with focal mechanisms that occurred in two-month time windows before and after ETS times, respectively. Pink, thin blue, and green crosses indicate the seismicity in two-month time windows before and after the ETS times. Yellow stars indicate LFEs located by previous studies ${ }^{21,22}$. Orange stars in Figs. 2a, 2c and $2 \mathrm{~d}$ and orange small open dots in Figs. $2 \mathrm{a}$ and $2 \mathrm{~b}$ indicate repeating earthquakes ${ }^{24}$ and a cluster of interplate 
events, respectively. (e) and (f) Results of stress tensor inversions for the upper-plane events beneath the region updip of the ETS zone for the combined regions $A+B+C$. Lower-hemisphere projections of $\sigma 1, \sigma 2$, and $\sigma 3$, indicated by black circles, crosses, and squares, respectively, of the best-fitting stress tensors before and after ETS times (See Table S1.) The 90\% confidence limits are depicted by the distributions of red, green, and blue dots, respectively. Note the shallowing of $\sigma 1$ after ETS. Red lines indicate the orientation of the slab interface. Input data to the inversions are shown in Fig. S1. (g) and (h) Results for the upper-plane events beneath the ETS zone. (i) and (j) Results for the interplane and lower-plane events. 

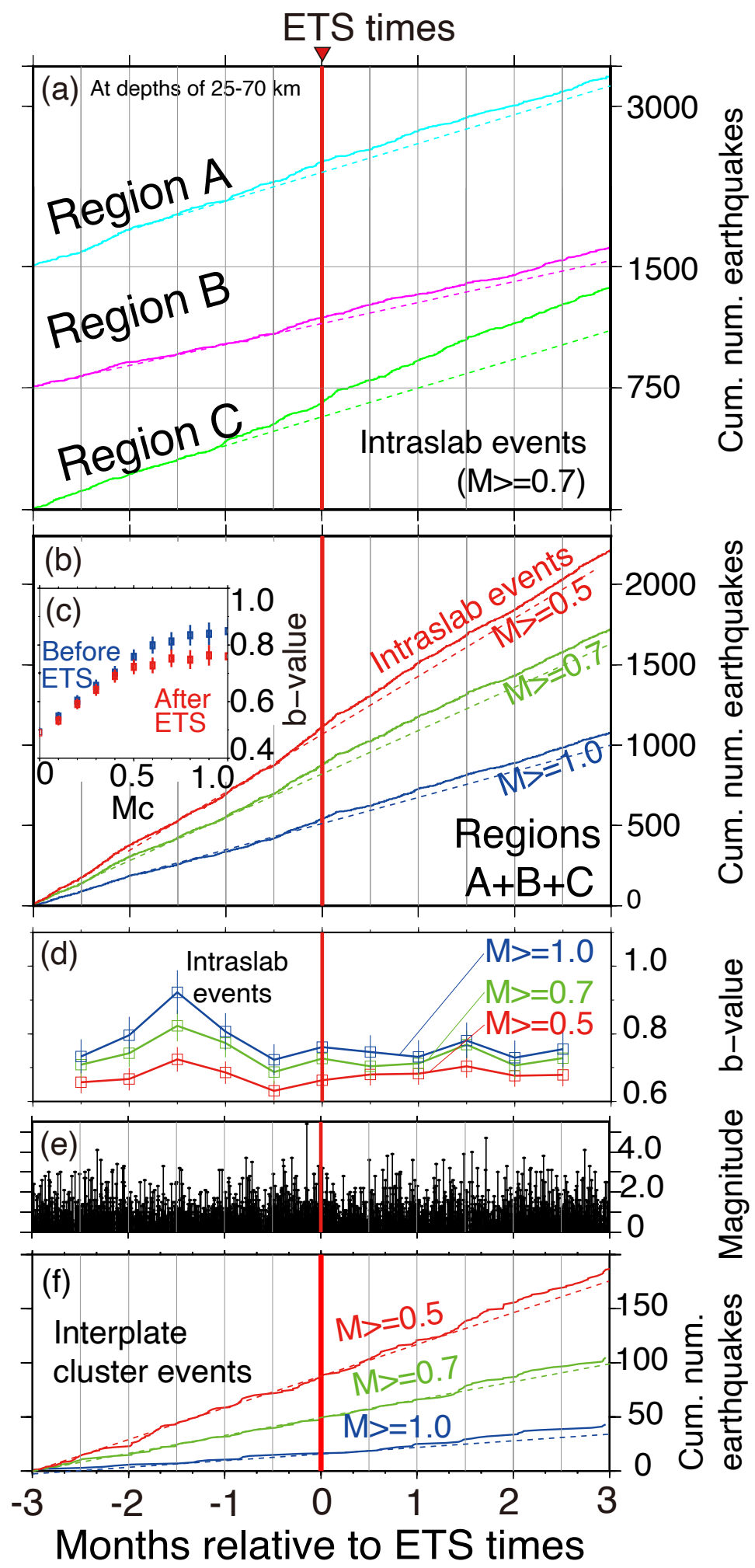

Fig. 3. Seismicity changes versus time relative to ETS times. (a) Cumulative numbers of seismicity deeper than $25 \mathrm{~km}$ in the three regions assuming that the lower limit of analysis magnitude, Mc, is 0.7 . Note increased seismicity rates appear to start approximately two to four weeks before ETS times and decrease after ETS times. (b) Cumulative numbers of seismicity in the combined region assuming different levels of completeness $(\mathrm{Mc}=0.5,0.7$, 1.0). Increased seismicity rates appear to start approximately two weeks before ETS times and decrease after ETS times. (c) b-values versus Mc for the combined region. Blue and red dots 
470 indicate b-values for events that occurred in two-month time windows before and after ETS times, respectively. Note the decrease in b-values for most values of Mc. An assumed Mc of 0.7 is the preferred value. (d) b-value time variation of in-slab events for the combined region using one-month moving windows. Red, green, and blue dots indicate the estimated b-values using Mc of 0.5, 0.7, and 1.0, respectively. Note high b-values peak six weeks before ETS times. (e) Magnitude of events. (f) Cumulative numbers of seismicity in the interplate event cluster in the region updip of the ETS zone indicated by orange dots in Figs. 2a and 2b. 


\section{2-1 month before ETS}

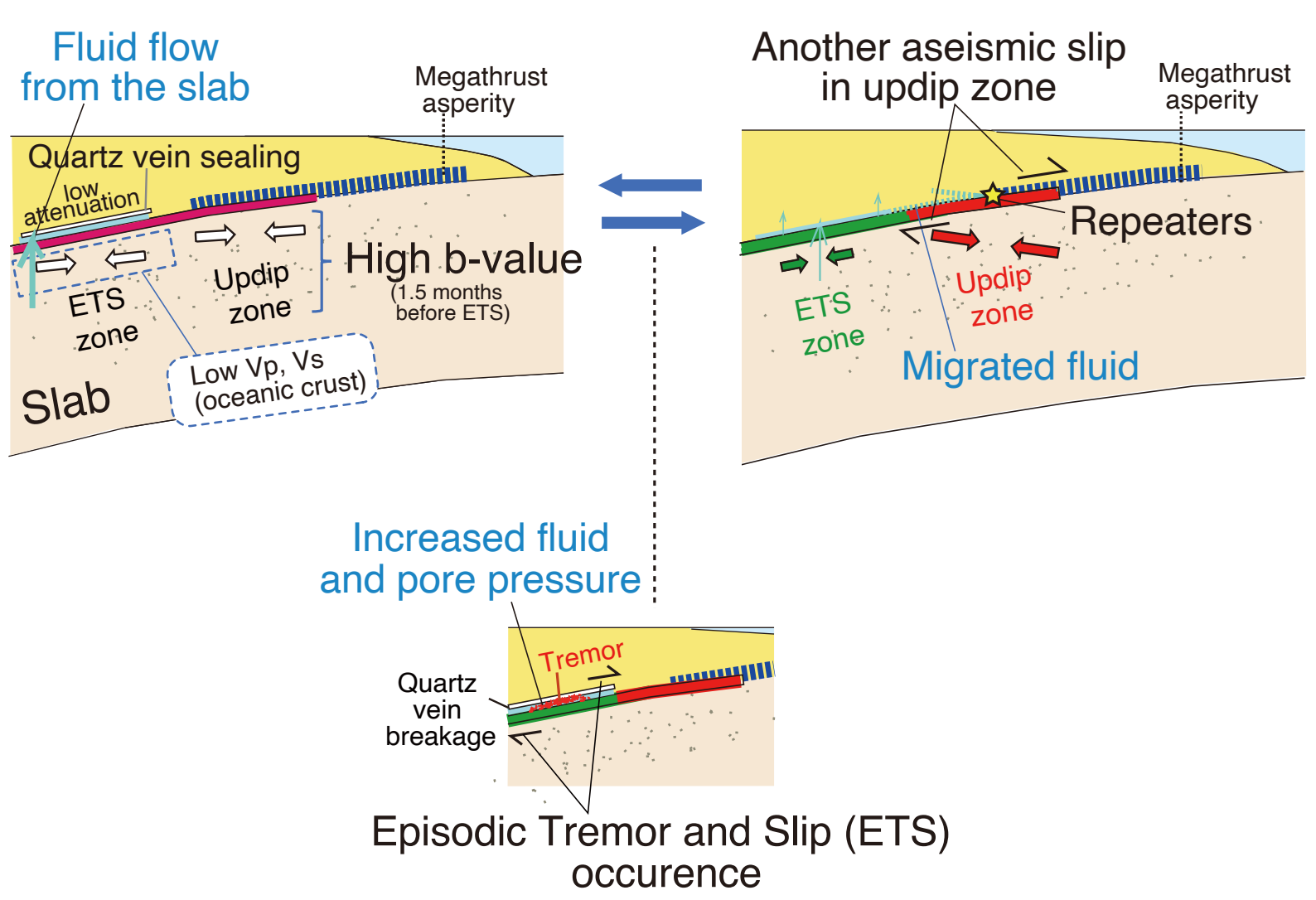

0-2 months after ETS

Fig. 4: Schematic cross-sectional views beneath Kii Peninsula before and after the occurrence of ETS. The stress state of upper-plane events in the slab changes after ETS times. Red and green arrows depict the orientations of maximum compressional stresses. Fluids move from the oceanic plate into the plate boundary, as suggested by the high b-value peak for the upper-plane events 1.5 months before ETS times. Increased fluid on the plate boundary reduces the degree of plate coupling between the overlying and subducting plates. 


\section{Supplementary Files}

This is a list of supplementary files associated with this preprint. Click to download.

- supplysubmitNGEO.pdf 